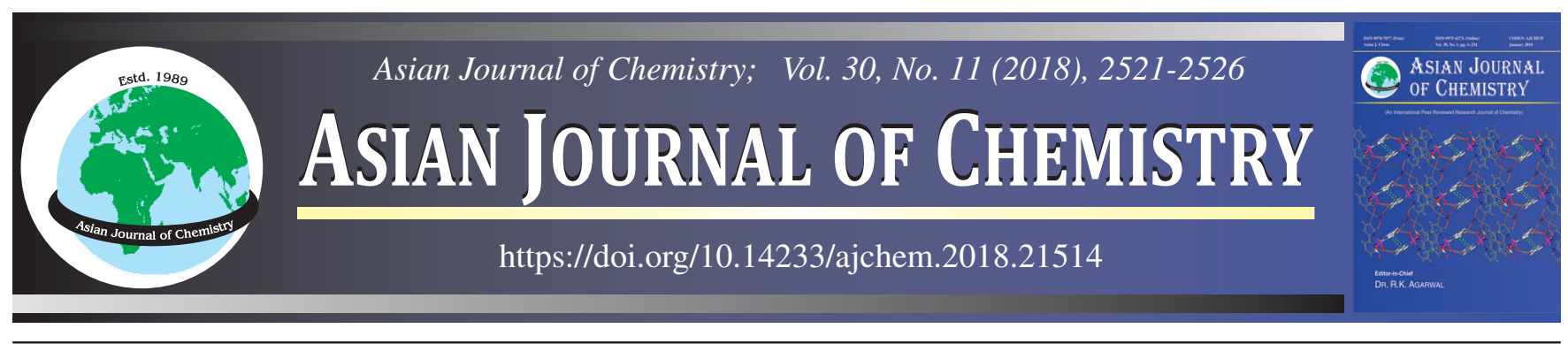

\title{
Qualitative and Quantitative Phytochemical Analysis of Leaves and Roots of Barleria dinteri with Varying Exposure to Road-Dust Pollution
}

\section{Ntholo Ishmael Molefe, Motetelo Alfred Mogale and Sechene Stanley Gololo*}

Department of Biochemistry, School of Science and Technology, Sefako Makgatho Health Sciences University, P.O. Box 235, Medunsa 0204, Pretoria, Republic of South Africa

*Corresponding author: Tel: +2712 521 4372; E-mail: Stanley.gololo@smu.ac.za

Received: 13 June 2018; Accepted: 13 August 2018;

Published online: 27 September 2018; AJC-19105

\begin{abstract}
The aim of the study was to undertake qualitative and quantitative phytochemical analysis of the samples of an African traditional herb, Barleria dinteri, with varying exposure to road-dust pollution. Both leaves and roots samples of $B$. dinteri were collected at two collection sites, one near a dusty road (test sample) and another away from a dusty road (control sample) in Zebediela sub-region of the Limpopo province of South Africa. The sample extracts were subjected to qualitative phytochemical analysis through chemical tests, thin layer chromatography and ultraviolet-visible spectrophotometry. The sample extracts were also subjected to spectrophotometric quantitative analysis of total phenolic content, total tannin content, total flavonoid content and total saponin content. Qualitative analysis results showed no substantial differences in the phytochemical compositions of the extracts obtained from test and control samples. Quantitative analysis results showed higher amounts of total phenolic, total tannin, total flavonoid and total saponin contents in the leaf test sample extracts than those of the control sample. Total phenolic and flavonoid contents were also present in higher amounts in the root test sample, whereas total tannins were higher in the control sample. The results demonstrate that the exposure to road-dust pollution have some moderate effect on the quality of phytochemicals possessed by the leaves and roots of $B$. dinteri, although substantial quantitative effect in the phytochemicals was demonstrated. The findings of the study therefore suggest that the exposure to road-dust pollution enhance accumulation in the phytochemicals possessed by Barleria dinteri, more especially in the leaves.
\end{abstract}

Keywords: Road-dust pollution, Phytochemical quality, Phytochemical screening, Phytochemical accumulation, Barleria dinteri. ᄂ - - - - - - - - - - - - - - - - - - - - - - - - - - - - - - -

\section{INTRODUCTION}

Medicinal plants in South Africa have been utilized for many years by indigenous people as remedies for human diseases because they contain components of therapeutic value. Even today more than $60 \%$ of South Africans depend on the effectiveness of traditional medicinal plants as compared to synthetic medicines [1]. Diseases that have been managed traditionally using medicinal plants include malaria, epilepsy, infertility, convulsion, diarrhoea and other complications caused by fungal and bacterial infections [2]. The importance and efficacy of medicinal plants depends on the nature of phytochemicals they possess [3].

The usage of medicinal plants in traditional healthcare system is predominated by a phenomenon of convenient plant collection practice, based on easiness of access. This gives rise to the collection of the same plant species at growth locations with different environmental influences or exposure for usage in treatment of similar disease conditions, with some disparities in the phytochemical compositions of the collected plant material [4]. One such scenarios is the collection of plant species at varying distances to roads, including untarred roads that exposes plants to road-dust pollution. Road-dust pollution like many environmental factors may have effect on the quality of phytochemicals found in medicinal plants parts $[5,6]$. In a study by Leghari et al. [7], road dust pollution was shown to have a negative effect on the growth of a grape bearing plant, Vitis vinifera. One such plant species that is observably located both near and far away to dusty roads in Limpopo province of South Africa is Barleria dinteri, which variably exposes the plant species to road-dust pollution. However, the effect that differences in the exposure to road-dust pollution have on the

This is an open access journal, and articles are distributed under the terms of the Creative Commons Attribution-NonCommercial 4.0 International (CC BY-NC 4.0) License, which allows others to copy and redistribute the material in any medium or format, remix, transform, and build upon the material, as long as appropriate credit is given and the new creations are licensed under the identical terms. 
quality and quantity of the phytochemical composition of the plant species is not known.

Barleria dinteri, a member of the Acanthaceae family, is one such plant that was observed to be located both near dusty roads in rocky areas of the mostly rural Limpopo province of South Africa, with easy access and far away from the road, mostly into the dense bushes with difficulty of access. The easiness of access for the plant species located along the roads leads for such plants to be frequently collected for usage in traditional medicine compared to those located away from the roads. $B$. dinteri is used in traditional medicine to treat many disease including bacterial infections and some form of intestinal tumours [8]. Barleria plant species are reported to possess important phytochemicals such as alkaloids, flavonoids, tannins, saponins and anthraquinones [9].

The aim of this study was to undertake the qualitative and quantitative phytochemical analysis of the leaves and roots samples of $B$. dinteri collected at two locations with observable differences in exposure to road-dust pollution in order to determine the effect that road-dust pollution have on the quality and quantity of phytochemicals possessed by the plant species.

\section{EXPERIMENTAL}

The plant species, B. dinteri, was selected based on ethnobotanical usage in traditional medicine and its habitation both near and away from dusty roads. The roots and leaves samples were collected from Limpopo province of South Africa at two different locations, one location being near (test sample) a dusty-road and the other location being far (control sample) from the dusty-road, using convenient sampling method. The collected plant samples were authenticated by staff at the University of Limpopo Herbarium where the voucher specimen was deposited (UNIN 11118). The collected roots and leaves were washed with distilled water and dried at room temperature. Dried samples were ground to fine powder and stored using closed containers at room temperature in the dark until further usage.

Extraction: The ground plant samples $(5 \mathrm{~g})$ were extracted with $50 \mathrm{~mL}$ of hexane, dichloromethane, acetone and methanol by cold maceration extraction method in a serial exhaustive procedure. Tubes were vigorously shaken for $5 \mathrm{~min}$. After centrifugation at $2000 \mathrm{rpm}$ for $30 \mathrm{~min}$ the supernatant was decanted into pre-weighed labelled beakers.

\section{Qualitative phytochemical analysis}

TLC analysis of the extracts: Chemical constituents of the extracts were analyzed by thin layer chromatography (TLC) using aluminum-backed TLC plates (Merck, silica gel $60 \mathrm{~F}_{234}$ ) as described by Masoko and Eloff [10], with modifications. The TLC plates that were developed separately with three different eluent systems, i.e. ethyl acetate/methanol/water (16:8:2, $\mathrm{v} / \mathrm{v} / \mathrm{v})$ : [EMW] (higher polarity); chloroform/methanol (16:2, $\mathrm{v} / \mathrm{v})$ : [CM] (intermediate polarity); hexane/ethyl acetate (16:2, $\mathrm{v} / \mathrm{v})$ : [HE] (lower polarity). After development of chromatograms, compound bands were visualized by spraying with freshly prepared vanillin reagent $(0.5$ vanillin, $50 \mathrm{~mL}$ methanol, sulphuric acid) spraying reagents. The vanillin sprayed plates were carefully heated at $100{ }^{\circ} \mathrm{C}$ for colour development.
Compound bands were used to calculate $\mathrm{R}_{\mathrm{f}}$ values and the values were compared between similar solvents leaves and roots samples extracts.

UV-visible analysis: Plant extracts were re-dissolved in dimethyl sulfoxide to constitute $10 \mathrm{mg} / \mathrm{mL}$ of the extracts and diluted tenfold as described by Alebiosu and Yusuf [11], with slight modification. UV-visible spectral profiles of the diluted extracts were obtained using a CECIL 1021 spectrophotometer (Labotec, South Africa). Wavelengths of maximum absorbance were recorded and compared between similar solvent leaves and roots samples extracts.

Phytochemical screening: Extracts of different samples were screened for the presence of different phytochemicals using different standard tests for each phytochemical group as outlined in Table-1.

\begin{tabular}{llc}
\multicolumn{4}{c}{ TABLE-1 } \\
\multicolumn{2}{c}{$\begin{array}{c}\text { STANDARD PHYTOCHEMICAL SCREENING TESTS } \\
\text { FOR DIFFERENT PHYTOCHEMICAL GROUPS }\end{array}$} \\
\hline \multicolumn{1}{c}{ Secondary } \\
metabolites & \multicolumn{1}{c}{ Test performed } & Ref. \\
\hline Alkaloids & \multicolumn{1}{c}{ Dragendorff's test } & {$[12]$} \\
Anthraquinones & Borntrager's test & {$[12]$} \\
Cardiac glycosides & Kellar-Kiliani test & {$[13]$} \\
Flavonoids & Shinoda test & {$[12]$} \\
Phenols & Phenol test & {$[12]$} \\
Reducing sugars & Fehling test & {$[14]$} \\
Saponins & Frothing test/Foam test & {$[13]$} \\
Steroids & Liebermann-Burchardt test & {$[12]$} \\
Tannins & Braemer's test & {$[13]$} \\
Terpenoids & Salkowski test & {$[15]$} \\
\hline
\end{tabular}

\section{Quantitative phytochemical analysis}

Total phenolic content: Total phenolic contents of the extracts were determined through the Folin-Ciocalteu reagent method as described by Ghasemzadeh et al. [16], with some modifications. Briefly, $2.5 \mathrm{~mL}$ of $10 \%$ Folin-Ciocalteu reagent and $2 \mathrm{~mL}$ of $2 \%$ solution of sodium carbonate were added to $1 \mathrm{~mL}$ of plant extract. The resulting mixture was incubated for $15 \mathrm{~min}$ at room temperature. The absorbance of the samples was measured at $765 \mathrm{~nm}$. Gallic acid was used as a standard $(1 \mathrm{mg} / \mathrm{mL})$. All tests were performed in triplicates. The results were expressed as Gallic acid equivalent (mg GAE/g of extracted plant material).

Determination of total tannin content: Total tannin contents of the extracts were determined by Folin-Ciocalteu method as described by Marinova et al. [17]. About $0.1 \mathrm{~mL}$ of the sample extract was added to a volumetric flask $(10 \mathrm{~mL})$ containing $7.5 \mathrm{~mL}$ of distilled water and $0.5 \mathrm{~mL}$ of FolinCiocalteu phenol reagent, $1 \mathrm{~mL}$ of $35 \% \mathrm{Na}_{2} \mathrm{CO}_{3}$ solution and dilute to $10 \mathrm{~mL}$ with distilled water. The mixture was shaken well and kept at room temperature for $30 \mathrm{~min}$. A set of reference standard solutions of gallic acid (20, 40, 60, 80 and $100 \mu \mathrm{g} / \mathrm{mL})$ were also prepared. Absorbance for test and standard solutions were measured against the blank at $725 \mathrm{~nm}$ with an UV/visible spectrophotometer. The tannin content was expressed in terms of gallic acid equivalence (mg GAE/g) of extract.

Total flavonoids content: Total flavonoid contents of the extracts were determined using the aluminum chloride 
colorimetric method as described by Ghasemzadeh et al. [16], with some modifications. Briefly, $1 \mathrm{~mL}$ of sample plant extract was mixed with $3 \mathrm{~mL}$ of methanol, $0.2 \mathrm{~mL}$ of $10 \%$ aluminum chloride, $0.2 \mathrm{~mL}$ of $1 \mathrm{M}$ potassium acetate and $5.6 \mathrm{~mL}$ of distilled water and remains at room temperature for $30 \mathrm{~min}$. The absorbance was measured at $420 \mathrm{~nm}$. Quercetin was used as standard $(1 \mathrm{mg} / \mathrm{mL})$. All the tests were performed in triplicates. Flavonoids contents were determined from the standard curve and were expressed as quercetin equivalent ( $\mathrm{mg} \mathrm{QE/g)} \mathrm{of} \mathrm{extracted}$ plant material.

Total saponins content: Total saponin contents of the extracts were determined using the vanillin-sulphuric acid colorimetric reaction as described by Makkar et al. [18]. About $50 \mu \mathrm{L}$ of plant extract was added with $250 \mu \mathrm{L}$ of distilled water. To this, about $250 \mu \mathrm{L}$ of vanillin reagent $(800 \mathrm{mg}$ of vanillin in $10 \mathrm{~mL}$ of $99.5 \%$ ethanol) was added. Then $2.5 \mathrm{~mL}$ of $72 \%$ sulphuric acid was added and it was mixed well. This solution was kept in a water bath at $60{ }^{\circ} \mathrm{C}$ for $10 \mathrm{~min}$. After $10 \mathrm{~min}$, it was cooled in ice cold water and the absorbance was read at $544 \mathrm{~nm}$. The values were expressed as diosgenin equivalents (mg DE/g extract) derived from a standard curve.

Statistical analysis: Quantitative data was analyzed for significant difference amongst groups by analyses of variance (ANOVA) using SPSS (version 12.00) statistical package, with significant difference demonstrated at $\mathrm{p}<0.05$.

\section{RESULTS AND DISCUSSION}

The extracts of the leaves and roots samples of $B$. dinteri from two locations with varying exposure to road-dust pollution were subjected to TLC analysis, UV-visible analysis and phytochemical screening. TLC chromatograms developed in mobile phases of different polarities and sprayed with vanillin/ sulphuric acid reagent showed some differences in resolved compounds bands amongst the extracts of the leaves and roots samples from two locations, with some compound bands visualized in samples from one location that are absent in similar solvent extracts of the samples from another location. The results of $R_{f}$ values of TLC resolved compound bands are presented in Table-2. The number of compound bands undetected on TLC chromatograms of samples from one location that were present in samples from another location were recorded and the results are presented in Table-3. A higher number of such compound bands were recorded in leaves (34) compared to those of the roots (23).

The UV-visible analysis and the phytochemical screening results for the leaves and roots samples with varying exposure to road-dust pollution are shown in Tables 4 and 5, respectively. The recorded maximum absorbance wavelengths from the absorbance spectra of extracts from both samples were mostly similar with the exception of the acetone control leaf sample

\begin{tabular}{|c|c|c|c|c|c|c|c|c|c|c|c|c|c|c|c|}
\hline \multicolumn{16}{|c|}{$\begin{array}{l}\text { TABLE-2 } \\
\mathrm{R}_{\mathrm{f}} \text { VALUES OF RESOLVED COMPOUND BANDS WITHIN THE EXTRACTS OF THE LEAVES AND ROOTS SAMPLES } \\
\text { OF B. dinteri COLLECTED AT TWO LOCATIONS WITH VARYING EXPOSURE TO ROAD-DUST POLLUTION }\end{array}$} \\
\hline \multicolumn{4}{|c|}{$n$-Hexane extracts } & \multicolumn{4}{|c|}{ Dichloromethane extracts } & \multicolumn{4}{|c|}{ Acetone extracts } & \multicolumn{4}{|c|}{ Methanol extracts } \\
\hline LC & LT & $\mathrm{RC}$ & RT & $\mathrm{LC}$ & LT & $\mathrm{RC}$ & RT & LC & LT & $\mathrm{RC}$ & RT & LC & LT & $\mathrm{RC}$ & RT \\
\hline \multicolumn{16}{|c|}{ Mobile phase: Hexane: Ethyl acetate $(9: 1, \mathrm{v} / \mathrm{v})$; lower polarity } \\
\hline 0.10 & 0.10 & - & 0.14 & - & 0.04 & 0.10 & 0.09 & - & 0.14 & 0.02 & 0.03 & 0.02 & 0.02 & 0.04 & 0.03 \\
\hline- & 0.20 & 0.22 & 0.25 & 0.10 & - & 0.18 & 0.18 & - & 0.24 & 0.30 & - & - & 0.30 & 0.33 & - \\
\hline- & 0.38 & 0.40 & 0.36 & 0.16 & - & - & 0.22 & 0.30 & 0.30 & 0.83 & 0.82 & 0.36 & - & 0.82 & - \\
\hline \multirow[t]{6}{*}{0.98} & 0.98 & - & 0.53 & 0.24 & 0.24 & 0.28 & - & 0.34 & 0.34 & 0.95 & 0.96 & & & 0.95 & - \\
\hline & & 0.60 & 0.64 & 0.30 & 0.32 & 0.32 & 0.42 & - & 0.44 & & & & & & \\
\hline & & 0.84 & 0.75 & - & 0.50 & 0.50 & 0.50 & & & & & & & & \\
\hline & & 0.96 & 0.96 & - & 0.60 & 0.60 & 0.63 & & & & & & & & \\
\hline & & & & 0.90 & 0.92 & 0.92 & 0.84 & & & & & & & & \\
\hline & & & & - & 0.98 & 0.98 & 0.96 & & & & & & & & \\
\hline \multicolumn{16}{|c|}{ Mobile phase: Chloroform: Methanol $(9: 1, \mathrm{v} / \mathrm{v})$; intermediate polarity } \\
\hline- & 0.05 & 0.96 & 0.96 & 0.58 & - & 0.36 & 0.36 & 0.58 & 0.58 & 0.25 & 0.24 & 0.15 & - & 0.18 & 0.18 \\
\hline 0.36 & - & & & 0.76 & - & 0.56 & 0.56 & 0.76 & - & 0.32 & 0.32 & 0.20 & - & 0.24 & 0.24 \\
\hline 0.41 & - & & & 0.86 & 0.88 & 0.58 & - & - & 0.84 & 0.36 & 0.36 & 0.28 & 0.32 & 0.32 & 0.32 \\
\hline \multirow[t]{7}{*}{0.90} & 0.90 & & & 0.96 & - & 0.64 & 0.64 & - & 0.90 & 0.40 & 0.40 & 0.36 & - & 0.36 & 0.36 \\
\hline & & & & & & - & 0.73 & 0.98 & 0.98 & 0.58 & 0.58 & 0.41 & 0.40 & 0.41 & 0.42 \\
\hline & & & & & & 0.88 & - & & & 0.64 & - & 0.58 & 0.59 & 0.58 & 0.58 \\
\hline & & & & & & 0.95 & 0.96 & & & 0.72 & 0.72 & 0.73 & - & 0.72 & 0.72 \\
\hline & & & & & & & & & & - & 0.76 & - & 0.83 & 0.75 & - \\
\hline & & & & & & & & & & 0.88 & 0.88 & 0.98 & 0.98 & 0.98 & 0.96 \\
\hline & & & & & & & & & & 0.98 & 0.98 & & & & \\
\hline \multicolumn{16}{|c|}{ Mobile phase: Ethyl acetate: Methanol: Water $(8: 4: 1, \mathrm{v} / \mathrm{v} / \mathrm{v})$; higher polarity } \\
\hline- & 0.50 & 0.83 & - & 0.76 & - & 0.83 & 0.85 & 0.76 & 0.76 & - & 0.84 & 0.32 & - & - & 0.19 \\
\hline 0.96 & 0.96 & 0.98 & 0.98 & 0.83 & 0.81 & - & 0.93 & 0.83 & 0.83 & 0.91 & 0.91 & 0.58 & 0.58 & - & 0.32 \\
\hline & & & & 0.86 & - & 0.96 & 0.98 & 0.86 & - & - & 0.98 & 0.63 & 0.63 & - & 0.56 \\
\hline & & & & 0.99 & 0.96 & & & 0.99 & 0.96 & & & 0.76 & 0.76 & - & 0.65 \\
\hline & & & & & & & & & & & & - & 0.83 & - & 0.73 \\
\hline & & & & & & & & & & & & 0.85 & 0.85 & - & 0.76 \\
\hline & & & & & & & & & & & & - & 0.88 & - & 0.83 \\
\hline & & & & & & & & & & & & 0.98 & 0.98 & 0.91 & - \\
\hline & & & & & & & & & & & & & & - & 0.98 \\
\hline
\end{tabular}


TABLE-3

UNDETECTED COMPOUND BANDS ON TLC CHROMATOGRAMS OF EXTRACTS OF $B$. dinteri LEAVES AND ROOTS SAMPLES FROM ONE LOCATION THAT ARE PRESENT IN SIMILAR SOLVENT EXTRACTS OF SAMPLES FROM THE OTHER LOCATION

\begin{tabular}{lcccc}
\hline \multirow{2}{*}{ Mobile phase } & \multicolumn{3}{c}{ Number of bands } \\
\cline { 2 - 5 } & Leaves control sample & Leaves test sample & Roots control sample & Roots test sample \\
\hline Hexane: Ethyl acetate $(9: 1, \mathrm{v} / \mathrm{v})$ & 10 & 3 & 3 & 5 \\
Chloroform: Methanol $(9: 1, \mathrm{v} / \mathrm{v})$ & 4 & 10 & 2 & 4 \\
Ethyl acetate: Methanol: Water $(8: 4: 1, \mathrm{v} / \mathrm{v} / \mathrm{v})$ & 3 & 4 & 8 & 13 \\
$\quad$ TOTAL & 17 & 17 & 10 \\
\hline \multicolumn{1}{c}{ Total per parts } & Leaves: $34^{*}$ & & Roots: $23^{*}$ \\
\hline *Significantly different at $\mathrm{p}<0.05$ & &
\end{tabular}

\begin{tabular}{|c|c|c|c|c|}
\hline \multicolumn{5}{|c|}{$\begin{array}{c}\text { TABLE-4 } \\
\text { MAXIMUM ABSORBANCE WAVELENGTHS }\left(\lambda_{\text {max }}\right) \text { RECORDED FOR EXTRACTS OF THE LEAVES AND } \\
\text { ROOTS SAMPLES OF } B \text {. dinteri WITH VARYING EXPOSURE TO ROAD-DUST POLLUTION }\end{array}$} \\
\hline \multirow{2}{*}{ Samples } & \multicolumn{4}{|c|}{$\lambda_{\max }$ values $(\mathrm{nm})$} \\
\hline & $n$-Hexane extracts & Dichloromethane extracts & Acetone extracts & Methanol extracts \\
\hline Leaves control sample & 200 & 200 & 200,260 & 200 \\
\hline Leaves test sample & 200 & 200 & 200 & 200 \\
\hline Roots control sample & 200 & 200 & 200,260 & 200 \\
\hline Roots test sample & 200 & 200 & 200 & 200,320 \\
\hline
\end{tabular}

\begin{tabular}{|c|c|c|c|c|c|c|c|c|c|c|c|c|c|c|c|c|}
\hline \multirow{3}{*}{ Phytochemicals } & \multicolumn{15}{|c|}{$\begin{array}{l}\text { TABLE-5 } \\
\text { PHYTOCHEMICAL SCREENING OF THE EXTRACTS OF THE LEAVES AND ROOTS } \\
\text { SAMPLES OF B. dinteri WITH VARYING EXPOSURE TO ROAD-DUST POLLUTION }\end{array}$} & \\
\hline & \multicolumn{4}{|c|}{ Hexane } & \multicolumn{4}{|c|}{ DCM } & \multicolumn{4}{|c|}{ Acetone } & \multicolumn{4}{|c|}{ Methanol } \\
\hline & $\mathrm{LC}$ & LT & $\mathrm{RC}$ & RT & $\mathrm{LC}$ & LT & $\mathrm{RC}$ & RT & $\mathrm{LC}$ & LT & $\mathrm{RC}$ & RT & $\mathrm{LC}$ & LT & $\mathrm{RC}$ & RT \\
\hline Alkaloids & - & - & - & - & - & - & - & - & + & + & + & + & + & + & + & + \\
\hline Flavonoids & - & - & - & + & - & - & - & + & ++ & ++ & ++ & ++ & + & + & + & ++ \\
\hline Glycosides & - & - & - & + & + & + & + & ++ & ++ & ++ & ++ & ++ & ++ & ++ & ++ & ++ \\
\hline Phenols & - & - & - & - & - & + & + & - & + & ++ & - & + & + & ++ & ++ & ++ \\
\hline Saponins & - & - & - & - & - & - & - & - & - & - & - & - & + & + & + & + \\
\hline Steroids & + & + & + & + & + & - & + & + & - & - & - & ++ & - & - & - & + \\
\hline Tannins & - & - & - & - & + & + & + & - & - & + & + & + & ++ & + & + & ++ \\
\hline Terpenoids & - & - & + & + & - & - & - & + & + & + & + & + & + & + & + & + \\
\hline
\end{tabular}

LC: leaves control sample; LT: leaves test sample; RC: roots control sample; RT: roots test sample

extract, the acetone control root sample extract and the methanol test sample extract whereby two wavelengths of maximum absorbance were observed while not observed in their counterpart sample extracts. The phytochemical screening results showed most of the similarities in the phytochemical compositions of the two plants samples (i.e., test and control samples) with all tested phytochemicals present in one or more of the extracts of the samples. Phytochemicals were mainly detected to be present in the polar extracts (acetone and methanol extracts) except for the steroids which were mainly present in the nonpolar extracts ( $n$-hexane and dichloromethane extracts).

The quantitative phytochemical analysis of the leaves and roots of the test and control samples are shown in Tables 6 and 7 , respectively. The leaf extracts of the test sample showed higher amounts of total phenolic, total tannin and total flavonoid than those of the control sample. The roots extracts of the test sample also showed higher total phenolic and total flavonoid contents, while the control sample showed higher total tannin contents. Total saponin contents were not significantly different amongst the samples for both the leaves and the roots.

Qualitative and quantitative phytochemical analysis of medicinal plants is important as it affords the determination of the nature of phytochemicals possessed by the different plants parts as well as their amounts [19]. In the present study the nature of phytochemicals present in the leaves and roots of two samples of $B$. dinteri collected from two locations in Limpopo province (South Africa) with varying exposure to road-dust pollution were determined through thin layer chromatography, UV-visible analysis and chemical screening tests. In addition, the amounts of phytochemicals within the plant sample extracts were determined through spectrophotometric analysis.

The results obtained through the three analytical techniques for phytochemical analysis all showed only slight differences in the phytochemical composition profiles of the samples of $B$. dinteri with varying exposure to road-dust pollution. Through TLC analysis, the results showed slight differences in the polarities of compounds possesses by the leaves and roots of $B$. dinteri samples from the two locations, with many differences shown by $\mathrm{R}_{\mathrm{f}}$ values of detected compound bands observed and recorded in the leaves samples as (Table-3). In addition, slight differences were seen in the light absorbance patterns of compounds possessed by the extracts of the samples from the two locations as depicted by slight differences in the maximum absorbance wavelengths of similar solvent extracts. Furthermore, slight differences were also seen in the phytochemical compositions of the extracts of the samples from the 


\begin{tabular}{|c|c|c|c|c|c|c|c|c|}
\hline \multicolumn{9}{|c|}{$\begin{array}{c}\text { TABLE-6 } \\
\text { QUANTITATIVE PHYTOCHEMICAL ANALYSIS OF THE LEAVES OF } B \text {. dinteri } \\
\text { WITH VARYING EXPOSURE TO ROAD-DUST POLLUTION }\end{array}$} \\
\hline \multirow{2}{*}{ Extracts } & \multicolumn{2}{|c|}{$\begin{array}{l}\text { Total phenolic content (mg } \\
\text { GAE/g extract dry weight) }\end{array}$} & \multicolumn{2}{|c|}{$\begin{array}{c}\text { Total tannin content (mg } \\
\text { GAE/g extract dry weight) }\end{array}$} & \multicolumn{2}{|c|}{$\begin{array}{l}\text { Total flavonoid content (mg } \\
\text { QE/g extract dry weight) }\end{array}$} & \multicolumn{2}{|c|}{$\begin{array}{l}\text { Total saponin content (mg } \\
\text { DE/g extract dry weight) }\end{array}$} \\
\hline & $\begin{array}{c}\text { Test } \\
\text { sample }\end{array}$ & $\begin{array}{l}\text { Control } \\
\text { sample }\end{array}$ & $\begin{array}{c}\text { Test } \\
\text { sample }\end{array}$ & $\begin{array}{l}\text { Control } \\
\text { sample }\end{array}$ & $\begin{array}{c}\text { Test } \\
\text { sample }\end{array}$ & $\begin{array}{l}\text { Control } \\
\text { sample }\end{array}$ & $\begin{array}{c}\text { Test } \\
\text { sample }\end{array}$ & $\begin{array}{l}\text { Control } \\
\text { sample }\end{array}$ \\
\hline$n$-Hexane & nd & nd & $0.500 \pm 0.28$ & $0.026 \pm 0.098$ & nd & nd & nd & nd \\
\hline Dichloromethane & nd & nd & nd & nd & nd & nd & nd & nd \\
\hline Acetone & $6.93 \pm 0.980$ & $2.35 \pm 0.360$ & $19.0 \pm 0.080$ & $9.81 \pm 0.167$ & $1.42 \pm 0.152$ & $0.117 \pm 0.190$ & $0.45 \pm 0.760$ & $0.50 \pm 0.147$ \\
\hline Methanol & $0.763 \pm 0.016$ & $0.400 \pm 0.500$ & $7.63 \pm 0.242$ & $10.3 \pm 0.082$ & $0.49 \pm 0.480$ & $0.39 \pm 0.082$ & $0.68 \pm 0.250$ & $0.70 \pm 0.225$ \\
\hline Total & $7.69 *$ & $2.75^{*}$ & $27.1 *$ & $20.1 *$ & $1.91 *$ & $0.507^{*}$ & 1.13 & 1.20 \\
\hline
\end{tabular}

\begin{tabular}{|c|c|c|c|c|c|c|c|c|}
\hline \multicolumn{9}{|c|}{$\begin{array}{c}\text { TABLE-7 } \\
\text { QUANTITATIVE PHYTOCHEMICAL ANALYSIS OF THE ROOTS OF B. dinteri } \\
\text { WITH VARYING EXPOSURE TO ROAD-DUST POLLUTION }\end{array}$} \\
\hline \multirow{2}{*}{ Extracts } & \multicolumn{2}{|c|}{$\begin{array}{l}\text { Total phenolic content (mg } \\
\text { GAE/g extract dry weight) }\end{array}$} & \multicolumn{2}{|c|}{$\begin{array}{c}\text { Total tannin content (mg } \\
\text { GAE/g extract dry weight) }\end{array}$} & \multicolumn{2}{|c|}{$\begin{array}{l}\text { Total flavonoid content (mg } \\
\text { QE/g extract dry weight) }\end{array}$} & \multicolumn{2}{|c|}{$\begin{array}{l}\text { Total saponin content (mg } \\
\text { DE/g extract dry weight) }\end{array}$} \\
\hline & $\begin{array}{c}\text { Test } \\
\text { sample }\end{array}$ & $\begin{array}{l}\text { Control } \\
\text { sample }\end{array}$ & $\begin{array}{c}\text { Test } \\
\text { sample }\end{array}$ & $\begin{array}{l}\text { Control } \\
\text { sample }\end{array}$ & $\begin{array}{c}\text { Test } \\
\text { sample }\end{array}$ & $\begin{array}{l}\text { Control } \\
\text { sample }\end{array}$ & $\begin{array}{c}\text { Test } \\
\text { sample }\end{array}$ & $\begin{array}{l}\text { Control } \\
\text { sample }\end{array}$ \\
\hline$n$-Hexane & nd & nd & nd & nd & nd & nd & $0.407 \pm 0.065$ & $0.245 \pm 0.194$ \\
\hline Dichloromethane & nd & nd & nd & nd & nd & nd & nd & nd \\
\hline Acetone & $3.16 \pm 0.242$ & $0.610 \pm 0.030$ & $2.17 \pm 0.352$ & $6.71 \pm 0.040$ & $2.98 \pm 0.286$ & $0.087 \pm 0.222$ & $0.369 \pm 0.840$ & $0.162 \pm 0.082$ \\
\hline Methanol & $1.72 \pm 0.032$ & $1.62 \pm 0.001$ & $4.46 \pm 0.346$ & $14.3 \pm 0.356$ & $3.56 \pm 0.167$ & $0.931 \pm 0.125$ & $0.380 \pm 0.242$ & $0.546 \pm 0.417$ \\
\hline Total & $4.88 *$ & $2.23 *$ & $6.57 *$ & $21.0^{*}$ & $6.54 *$ & $1.02 *$ & 1.16 & 0.953 \\
\hline
\end{tabular}

two locations as determined through phytochemical screening tests. However, it is worth noting that the three techniques used in this study are limited to the detection of the classes of compounds present in plants extracts with less specificity to the actual compounds [20].

In contrast to the qualitative analysis results, the quantitative analysis results showed significantly different (i.e., $\mathrm{p}<$ 0.05 ) amounts of almost all analyzed phytochemicals between the test and control samples. In this regard, higher amounts of total phenolic, total tannin and total flavonoid contents were found in the test leaves sample as compared to those of the control leaves sample. Higher amounts of total tannin and total flavonoid contents were also found in the test roots sample compared to those of the control roots sample. However, the higher amounts of total tannin was found in the control roots sample as compared to those of the test sample control. Furthermore, the total saponin contents were not significantly different (i.e., $\mathrm{p}>0.05$ ) for both the leaves and roots samples. This non-conformity in the trend of quantitative results regarding which sample, either the test sample or the control sample, have higher amounts of phytochemicals throughout suggest an element of specificity of affected phytochemicals for their accumulation in plant parts. The results of the current study are therefore in agreement with the findings of Gololo et al. [21] on the specificity of the accumulation of phytochemicals in plants. The effect of road-dust pollution on the quality and quantity of phytochemicals in the leaves and roots of $B$. dinter $i$ is reported here for the first time.

\section{Conclusion}

The results of the present study suggest that the differences in exposure to road-dust pollution have moderate effect on the quality of the phytochemical composition of the leaves and roots of Barleria dinteri, although substantial effects could be seen in the quantity or accumulation of its phytochemicals. It appears, the most affected part of $B$. dinteri in the phytochemical composition upon exposure to road-dust pollutionis the leaves. The leaves are part of the above ground plants parts that are naturally exposed to dust pollution that might inform the observed results in the present study. The findings of the current study therefore supports the general principle that phytochemical composition of plants is affected by environmental conditions in which they are growing.

\section{ACKNOWLEDGEMENTS}

The authors acknowledge to Department of Biochemistry at Sefako Makgatho Health Sciences University for facilities to undertake this study, as well as Dr. Bronwyn Egan for assistance with taxonomic authentication of the collected plant samples. The study was carried with the support of funding from the Department of Higher Education and Training, Republic of South Africa through Research Development Grant awarded to Dr. S.S. Gololo (RDG: GOLOLO, D120).

\section{CONFLICT OF INTEREST}

The authors declare that there is no conflict of interests regarding the publication of this article.

\section{REFERENCES}

1. B.E. Van Wyk, B. Van Oudsthoorn and N. Gericke, Medicinal Plants of South Africa, Briza Publications: Pretoria, South Africa, pp. 1-336 (1997).

2. A. Maroyi, Afr. J. Tradit. Complement. Altern. Med., 13, 5 (2016); https://doi.org/10.21010/ajtcam.v13i6.2.

3. A. Wadood, M. Ghufran, S.B. Jamal, M. Naeem and A. Khan, Biochem. Anal. Biochem., 2, 1 (2013);

https://doi.org/10.4172/2161-1009.1000144. 
4. S.S. Gololo, N.S. Mapfumari, L.J. Shai, L. Sethoga, M.T. Olivier, F.M. Muganzaand and M.A. Mogale, eds.: A.A. Mahdi, M. Abid and M.M.A. Ali Khan, Disparities in the Phytochemical Constituents of the Leaf Samples of Senna italica (Mill) collected from Four Different Locations, In: Phytochemistry and Pharmacology of Medicinal Plants,Lenin Media Pvt Ltd.: Delhi, India, pp. 1-15 (2017).

5. M. Björkman, I. Klingen, A.N.E. Birch, A.M. Bones, T.J.A. Bruce, T.J. Johansen, R. Meadow, J. Mølmann, R. Seljåsen, L.E. Smart and D. Stewart, Phytochemistry, 72, 538 (2011); https://doi.org/10.1016/j.phytochem.2011.01.014..

6. U.A. Pamila and S. Karpagam, Int. Res. J. Biochem. Biotechnol., 4, 61 (2017).

7. S.K. Leghari, M.S. Zaid, A.M. Sarangzai and M. Faheem, Afr. J. Biotechnol., 13, 1237 (2013).

8. A. Ata, K.S. Kalhari and R. Samarasekera, Phytochem. Lett., 2, 37 (2009); https://doi.org/10.1016/j.phytol.2008.11.005

9. A.K. Maji, S. Bhadra, S. Mahapatra, P. Banerji and D. Banerjee, J. Pharmacogn., 3, 67 (2011); https://doi.org/10.5530/pj.2011.24.13.

10. P. Masoko and J.N. Eloff, Afr. J. Tradit. Complement. Altern. Med., 4, 231 (2007)

11. C. Alebiosu and Y. Yusuf, J. Pharm. Chem. Biol. Sci., 3, 214 (2015).

12. A. Kumar and S. Sharma, Ind. Crops Prod., 28, 1 (2008); https://doi.org/10.1016/j.indcrop.2008.01.001.
13. J. Parekh and S. Chanda, Afr. J. Biotechnol., 6, 766 (2007).

14. K.O. Akinyemi, O. Oladapo, C.E. Okwara, C.C. Ibe and K.A. Fasure, BMC Complement. Altern. Med., 5, 6 (2005); https://doi.org/10.1186/1472-6882-5-6.

15. H.O. Edeoga, D.E. Okwu and B.O. Mbaebie, Afr. J. Biotechnol., 4, 685 (2005); https://doi.org/10.5897/AJB2005.000-3127.

16. A. Ghasemzadeh, H.Z.E. Jaafar, A. Rahmat, P.E.M. Wahab and M.R. Abd Halim, Int. J. Mol. Sci., 11, 3885 (2010); https://doi.org/10.3390/ijms11103885.

17. D. Marinova, F. Ribarova and M. Atanassova, J. Univ. Chem. Technol. Metall., 40, 255 (2005).

18. H.P. Makkar, P. Siddhuraju and K. Becker, Methods in Molecular Biology: Plant Secondary Metabolites, Human Press, Totowa, pp. 93-100 (2007).

19. J. Senguttuvan, S. Paulsamy and K. Karthika, Asian Pac. J. Trop. Biomed., 4, S359 (2014); https://doi.org/10.12980/APJTB.4.2014C 1030.

20. A. Altemimi, N. Lakhssassi, A. Baharlouei, D. Watson and D. Lightfoot, Plants, 6, 42 (2017); https://doi.org/10.3390/plants6040042.

21. S.S. Gololo, L.J. Shai, N.M. Agyei and M.A. Mogale, J. Pharmacogn. Phytother., 8, 168 (2016); https://doi.org/10.5897/JPP2016.0408. 